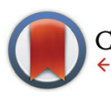

CrossMark

Cite this: Food Funct., 2016, 7, 1554

\title{
White adipose tissue urea cycle activity is not affected by one-month treatment with a hyperlipidic diet in female rats $\uparrow$
}

\author{
Sofía Arriarán, ${ }^{a}$ Silvia Agnelli, ${ }^{a}$ Xavier Remesar, ${ }^{\text {a,b,c }}$ Marià Alemany ${ }^{a, b, c}$ and \\ José Antonio Fernández-López*a,b,c
}

\begin{abstract}
Under high-energy diets, amino acid $\mathrm{N}$ is difficult to dispose of, as a consequence of the availability of alternative substrates. We found, recently, that WAT contains a complete functional urea cycle, we analyzed the possible overall changes in the WAT urea cycle (and other-related amino acid metabolism gene expressions) in rats subjected to a cafeteria diet. Adult female Wistar rats were fed control or simplified cafeteria diets. Samples of WAT sites: mesenteric, periovaric, retroperitoneal and subcutaneous, were used for the estimation of all urea cycle enzyme activities and gene expressions. Other key amino acid metabolism gene expressions, and lactate dehydrogenase were also measured. Subcutaneous WAT showed a differentiated amino acid metabolism profile, since its cumulative (whole site) activity for most enzymes was higher than the activities of the other sites studied. After one month of eating an energyrich cafeteria diet, and in spite of doubling the size of WAT, the transforming capacity of most amino acid metabolism enzymes remained practically unchanged in the tissue. This was not only due to limited changes in the overall enzyme activity, but also a consequence of a relative decrease in the expression of the corresponding genes. Overall, the results of this study support the consideration of WAT as an organ, disperse but under uniform control. The metabolic peculiarities between its different sites, and their ability to adapt to different energy availability conditions only add to the variable nature of adipose tissue. We have presented additional evidence of the significant role of WAT in amino acid metabolism.
\end{abstract}

Received 4th December 2015 Accepted 5th February 2016

DOI: 10.1039/c5fo01503k

www.rsc.org/foodfunction that availability and lower its storage of fat. In that process, WAT also releases a number of adipokines, ${ }^{8}$ which tend to help activate the defense systems and metabolic adaptations to face off the problem of disposal of excess available energy. ${ }^{9}$

The key point is the massive glucose-fueled lipogenesis, since the WAT insulin response is better maintained, under conditions of generalized insulin resistance, than in other peripheral organs and the liver. ${ }^{10}$ Thus, the adipocyte could not fully prevent the uptake of high circulating glucose other than decreasing blood flow, ${ }^{7}$ which may elicit hypoxia, ${ }^{11}$ and lower the synthesis of acyl-glycerols. We have found recently that both cultured 3T3-L1 adipocytes, ${ }^{12}$ and rat WAT in vivo, ${ }^{13}$ break up inordinate amounts of glucose to release 3C units, largely lactate. ${ }^{12-14}$ This is a consequence of the diversion of pyruvate towards lactate instead of entering the mitochondria and producing acetyl-CoA, the key building block of acyl-CoA. Reduced oxidative metabolism facilitates the process; in vivo studies in humans and rats have shown low oxygen levels in WAT without signs of hypoxia. ${ }^{15,16}$ This "normal hypoxia" is linked to low WAT oxygen consumption in vivo. ${ }^{16}$ Evidently, these data contrast with the obvious hypertrophic and hyper- 
plasic growth of WAT when the adipocyte is exposed to abundant glucose. Curiously, in cultured adipocytes, differentiation from fibroblast and massive accumulation of fat, at high medium glucose levels, is continued by a massive breakup to lactate of this same glucose when the cells are mature and their fat stores are large. ${ }^{13}$ Therefore, lipogenesis and the potential resistance to hypoxia run in parallel, i.e. the hypertrophic WAT response to excess glucose and oxygen needs should be markedly different from a basal or cell energystarved state, when lipogenesis is highly stimulated.

Amino acid metabolism is not generally included in overall energy metabolism analyses, in part because of its complexity, usually limited provision of energy, and its direct implication with a number of biosynthetic paths, of which protein synthesis is paramount for survival. However, all cells have a significant amino acid metabolism, despite the central role of liver and other organs of the splanchnic bed, ${ }^{17,18}$ since they play the double role of controlling the dietary supply of amino acids and are the main site for the final conversion of 2-amino $\mathrm{N}$ to ammonium, and finally urea.

The mechanisms of preservation of 2-amino $\mathrm{N}$ have evolved to powerful fail-safe mechanisms, which prevent the loss of hard-to-obtain amino acids. ${ }^{19,20}$ However, high-energy highquality protein diets tend to create havoc in the mechanisms of regulation of amino acid metabolism: cafeteria diets decrease the excretion of urea $\mathrm{N}$ in spite of maintained (or increased) $\mathrm{N}$ intake; ${ }^{21}$ the form of excretion of excess $\mathrm{N}$ which could not be stored in significant amounts-is unknown. ${ }^{22,23}$ In this context the role of WAT is, usually, not even considered, in part because of the wrongly perceived low global metabolic activity of the tissue and our superficial knowledge of amino acid metabolism in WAT. ${ }^{24}$ We have found, recently, that WAT contains a complete and functional urea cycle, ${ }^{25}$ which makes our assumptions of how 2-amino $\mathrm{N}$ is disposed of even more complicated, especially under conditions of obesity/inflammation, since an increase in the WAT mass could result in a parallel increase in its ability to dispose of 2-amino $\mathrm{N}$. In the present study, we have analyzed in detail the possible overall changes in the WAT urea cycle (and otherrelated amino acid metabolism gene expressions) in female rats subjected to a cafeteria diet compared with controls. The comparisons have been done essentially by comparing the whole WAT site enzyme activity (or gene expression) of control and cafeteria diet-fed rats to better understand their possible influence on the whole body amino acid handling capability.

\section{Materials and methods}

\section{Experimental design and animal handling}

All animal handling procedures and the experimental setup were in accordance with the animal handling guidelines of the corresponding European and Catalan Authorities. The Committee on Animal Experimentation of the University of Barcelona specifically authorized the procedures used in the present study.
Nine week old female Wistar rats (Harlan Laboratory Models, Sant Feliu de Codines, Spain) were used. Six animals per group were housed in two-rat cages and had free access to water. The animals were kept in a controlled environment (lights on from 08:00 to $20: 00 ; 21.5-22.5{ }^{\circ} \mathrm{C}$; $50-60 \%$ humidity). Two groups were randomly selected and were fed ad libitum, for 30 days, with either normal rat chow (\#2014, Harlan) or a simplified cafeteria diet: ${ }^{26}$ chow pellets, plain cookies, with liver pâté, bacon, whole milk containing $300 \mathrm{~g}$ per L sucrose and a mineral and vitamin supplement. We used the procedures for food intake estimation and analysis previously described. ${ }^{27}$ The estimated diet intake composition was (expressed as energy content): carbohydrate $67 \%$, protein $20 \%$, and lipid $13 \%$ for controls. That of rats fed the cafeteria diet (i.e. food ingested during the $30 \mathrm{~d}$ period studied) was: carbohydrate $47 \%$, protein $12 \%$ and lipid $41 \%$ (energy content). This diet induced a significant increase in body fat, and it has been used for a long time in studies on metabolic syndrome. ${ }^{26,28}$

The rats were killed, under isoflurane anesthesia, at the beginning of a light cycle by aortic exsanguination, using dryheparinized syringes; then, were rapidly dissected, taking samples of WAT sites: mesenteric (ME), periovaric (PO), retroperitoneal (RP) and subcutaneous (SC, inguinal fat pads). The samples were blotted, and frozen with liquid nitrogen. After weighing, they were ground under liquid nitrogen; sample aliquots were stored at $-80{ }^{\circ} \mathrm{C}$ until processed. Later, the dissection of the rats continued, extracting the remaining WAT in ME, EP and RP sites; the rats were skinned, and the whole subcutaneous WAT was dissected. The weights of the recovered WAT were added to obtain the total mass of each WAT site.

\section{Blood plasma parameters}

The blood obtained from the aorta puncture was centrifuged to obtain plasma, which was frozen and kept at $-80^{\circ} \mathrm{C}$ until processed. Plasma samples were used to measure glucose (kit \#11504), triacylglycerols (kit \#11828), total cholesterol (kit \#11505) and urea (kit \# 11537), all from Biosystems, Barcelona Spain). Lactate was measured with kit \#1001330 (Spinreac, Sant Esteve de Bas, Spain). Amino acids were analyzed individually with an amino acid analyzer (Pharmacia-LKB-Alphaplus, Uppsala, Sweden) using plasma samples deproteinized with acetone. ${ }^{29}$ Since the method used did not provide fair analyses for glutamine and other amino acids (Trp, Cys, Asn), we decided to present only the partial sum of the other amino acids as a single indicative value.

\section{Preparation of tissue homogenates}

Frozen tissue samples were homogenized, using a tissue disruptor (Ultraturrax IKA-T10, Ika Werke, Staufen, Germany), in 5 volumes of chilled $70 \mathrm{mM}$ hepes buffer $\mathrm{pH} 7.4$ containing $1 \mathrm{mM}$ dithiothreitol (Sigma-Aldrich, St Louis MO, USA), $50 \mathrm{mM} \mathrm{KCl,} 1 \mathrm{~g}$ per L Triton X-100 (Sigma) and $1 \mathrm{~g}$ per L lipidfree bovine serum albumin (Sigma-Aldrich). In homogenates to be used for carbamoyl-P synthase 2 estimation, the concentration of Triton X-100 was reduced to $0.5 \mathrm{~g}$ per $\mathrm{L}$ to 
Table 1 Primer sequences used in the analysis of WAT gene expressions

\begin{tabular}{|c|c|c|c|c|c|}
\hline Gene & Protein & EC & Primer sequence $5^{\prime}>3^{\prime}$ & Primer sequence $3^{\prime}>5^{\prime}$ & bp \\
\hline Cad & Glutamine-dependent carbamoyl-phosphate synthase & 6.3.5.5 & AGTTGGAGGAGGAGGCTGAG & ATTGATGGACAGGTGCTGGT & 90 \\
\hline Otc & Ornithine carbamoyl transferase & 2.1.3.3 & CTTGGGCGTGAATGAAAGTC & ATTGGGATGGTTGCTTCCT & 126 \\
\hline Ass1 & Arginino-succinate synthase & 6.3.4.5 & CAAAGATGGCACTACCCACA & GTTCTCCACGATGTCAATGC & 100 \\
\hline Asl & Arginino-succinate lyase & 4.3.2.1 & CCGACCTTGCCTACTACCTG & GAGAGCCACСССТTTCATCT & 104 \\
\hline Arg1 & Arginase-1 & 3.5.3.1 & GCAGAGACCCAGAAGAATGG & GTGAGCATCCACCCAAATG & 126 \\
\hline Arg2 & Arginase-2 & 3.5.3.1 & GCAGCCTCTTTCCTTTCTCA & CCACATCTCGTAAGCCAATG & 122 \\
\hline Nags & $\mathrm{N}$-Acetyl-glutamate synthase & 2.3.1.1 & GCAGCCCACCAAAATCAT & CAGGTTCACATTGCTCAGGA & 82 \\
\hline Nos3 & Nitric oxide synthase, endothelial & 1.14.13.39 & CAAGTCCTCACCGCCTTTT & GACATCACCGCAGACAAACA & 138 \\
\hline Glul & Glutamine synthetase & 6.3.1.2 & AACCCTCACGCCAGCATA & CTGCGATGTTTTCCTCTCG & 148 \\
\hline Gls & Glutaminase kidney isoform, mitochondrial & 3.5.1.2 & CCGAAGGTTTGCTCTGTCA & AGGGCTGTTCTGGAGTCGTA & 63 \\
\hline Glud1 & Glutamate dehydrogenase 1 , mitochondrial & 1.4.1.3 & GGACAGAATATCGGGTGCAT & TCAGGTCCAATCCCAGGTTA & 122 \\
\hline Gcsh & Glycine cleavage system $\mathrm{H}$ protein, mitochondrial & - & AAGCACGAATGGGTAACAGC & TCCAAAGCACCAAACTCCTC & 146 \\
\hline Ampd2 & AMP deaminase 2 & 3.5.4.6 & CGGCTTCTCTCACAAGGTG & CGGATGTCGTTACCCTCAG & 78 \\
\hline Gpt & Alanine aminotransfer & 2.6.1.2 & GTATTCCACGCAGCAGGAG & CACATAGCCACCACGAAACC & 85 \\
\hline Gpt2 & Alanine aminotransferase 2 & 2.6.1.2 & CATTCCCTCGGATTCTCATC & GCCTTCTCGCTGTCCAAA & 146 \\
\hline Bcat1 & $\begin{array}{l}\text { Branched-chain-amino-acid aminotransferase, } \\
\text { cytosolic }\end{array}$ & 2.6.1.42 & TGCCCAGTTGCCAGTATTC & CAGTGTCCATTCGCTCTTGA & 138 \\
\hline Bcat2 & $\begin{array}{l}\text { Branched-chain-amino-acid aminotransferase, } \\
\text { mitochondrial }\end{array}$ & 2.6.1.42 & AGTCTTCGGCTCAGGCACT & ATGGTAGGAATGTGGAGTTGCT & 84 \\
\hline Ldha & Lactic acid dehydrogenase muscle type (a) & 1.1.1.27 & CACTGGGTTTGAGACGATGA & GTCAGCAAGAGGGAGAGAGC & 125 \\
\hline$L d h b$ & Lactic acid dehydrogenase heart type (b) & 1.1.1.27 & CCAGGAACTGAACCCAGAGA & TCATAGGCACTGTCCACCAC & 131 \\
\hline Rplpo & $60 \mathrm{~S}$ acidic ribosomal protein 0 (housekeeping gene) & - & GAGCCAGCGAAGCCACACT & GATCAGCCCGAAGGAGAAGG & 62 \\
\hline
\end{tabular}

decrease foaming. The homogenates were centrifuged for $10 \mathrm{~min}$ at $5000 \mathrm{~g}$; the floating fat layers and debris precipitates were discarded. The clean homogenates were kept on ice, and used for enzyme analyses within $2 \mathrm{~h}$.

Tissue protein was estimated with the Lowry method, ${ }^{30}$ using finely powdered inert $\mathrm{MgO}$ to eliminate the remaining fat-generated turbidity after development of color. Homogenization buffer (which contained albumin) was used as blank. Enzyme activities were initially expressed in nkat per g protein.

\section{Enzyme activity analyses}

Carbamoyl-P synthase was estimated from the incorporation of

${ }^{14} \mathrm{C}$-bicarbonate (Perkin Elmer, Bad Neuheim, Germany) into carbamoyl-P using a method previously described by us. ${ }^{31}$

All other urea cycle enzyme activities (ornithine carbamoyltransferase, arginino-succinate synthase, arginino-succinate lyase and arginase) were estimated following our recently developed methods which are presented with detail in the Methods, ESI. $\dagger$

A modified UV method was used for lactate dehydrogenase activity. $^{32}$ The reaction mixture contained $150 \mu \mathrm{M} \mathrm{NADH}$, $125 \mathrm{mg}$ per L bovine serum albumin and $1 \mathrm{mM}$ sodium pyruvate (Sigma-Aldrich). The proportion of original tissue in each measuring well was in the range of $2.0-2.5 \mathrm{mg}$, in a volume of $0.02 \mathrm{~mL}$ of homogenate, diluted to the adequate proportions with homogenization medium. Absorbance at $340 \mathrm{~nm}$ was measured at intervals of $30 \mathrm{~s}$ for up to $10 \mathrm{~min}$. In each case, the decrease in absorbance, due to the formation of $\mathrm{NAD}^{+}$, was plotted, and initial $\left(V_{0}\right)$ activities were determined from the course of the reaction at different times.

\section{Gene expression analysis}

Total tissue RNA was extracted from frozen tissue samples using the Tripure reagent (Roche Applied Science, Indiana- polis IN, USA), and was quantified in an ND-100 spectrophotometer (Nanodrop Technologies, Wilmington DE, USA). RNA samples were reverse transcribed using the MMLV reverse transcriptase (Promega, Madison, WI, USA) system and oligo-dT primers. These data were also used to determine the total RNA content of the tissue (expressed per $g$ of tissue weight).

Real-time PCR (RT-PCR) amplification was carried out using $10 \mu \mathrm{L}$ amplification mixtures containing Power SYBR Green PCR Master Mix (Applied Biosystems, Foster City, CA, USA), $4 \mathrm{ng}$ of reverse-transcribed RNA and 150 nanomols of primers. Reactions were run on an ABI PRISM 7900 HT detection system (Applied Biosystems) using a fluorescent threshold manually set to 0.15 for all runs.

A semi-quantitative approach for the estimation of the concentration of specific gene mRNAs per unit of tissue/RNA or protein weight was used. ${ }^{33}$ Rplpo was the charge control gene. ${ }^{34}$ We expressed the data as the number of transcript copies per gram of protein in order to obtain comparable data between the groups. The genes analyzed and a list of primers used is presented in Table 1.

\section{Statistics}

One- and two-way ANOVA comparisons between groups and curve fitting (e.g. for Vi estimations) were analyzed with the Prism 5 program (GraphPad Software, San Diego, CA, USA).

\section{Results}

Fig. 1 shows that the rat weight changes within 30 days of feeding the cafeteria or control diets. Rats fed cafeteria diet gained more body weight and ended up weighing more than control animals. Table 2 shows the weights of the four WAT sites studied, as well as the levels of protein and RNA per $g$ of 


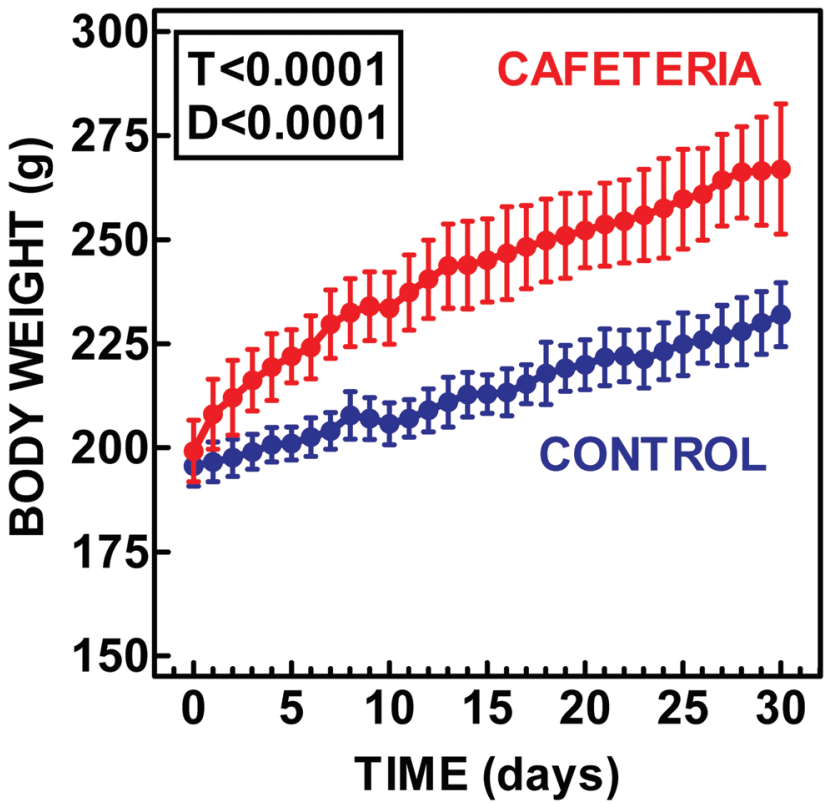

Fig. 1 Comparison of the body weight of female rats fed control or cafeteria diets. The data are the mean \pm SEM of 6 different animals. Statistical significance of the differences between groups (two-way ANOVA). T represents the $P$ value for "time" and D that for "diet".

adipose tissue. Both the differences for site and diet were statistically significant. Combined WAT weight of control rats for the four WAT sites was $8.1 \%$ of the body weight, compared with $15.2 \%$ for cafeteria rats. The difference in the body weight minus the sum of WAT sites was minimal for both the dietary groups (213 g controls, $226 \mathrm{~g}$ cafeteria), suggesting that WAT was, precisely, the main factor justifying the differences observed in the body weight. The differences induced by diet and those on WAT sites were also statistically significant for the protein content and total RNA. However, both protein and RNA tended to decrease in cafeteria rats when expressed per $g$ of tissue. The RNA/protein ratio decreased considerably in all WAT sites fed the cafeteria diet; the mesenteric ratio showing the highest, and subcutaneous WAT the lowest values.

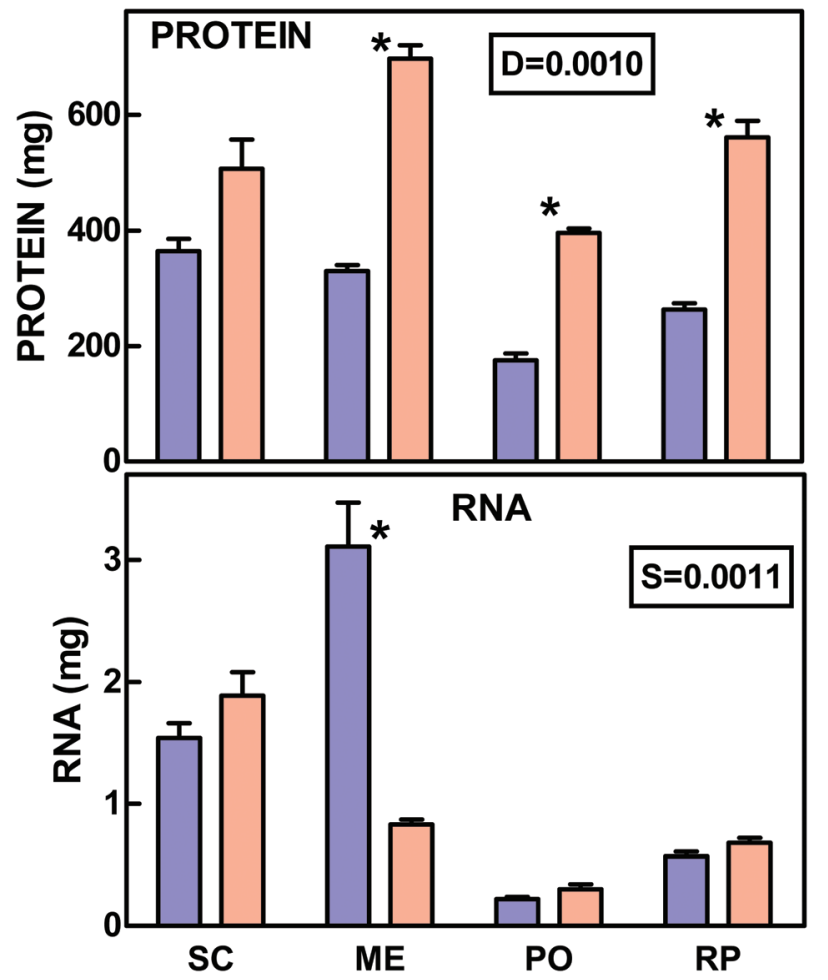

Fig. 2 Comparison of the protein and RNA content of the four main WAT sites of female rats fed control or cafeteria diets. The data are the mean \pm SEM of 6 different animals. Lilac columns: control diet; soft red columns: cafeteria diet. WAT sites: $\mathrm{SC}=$ subcutaneous, $\mathrm{ME}=$ mesenteric, $\mathrm{PO}=$ periovaric; $\mathrm{RP}=$ retroperitoneal. Statistical significance of the differences between groups (two-way ANOVA). S represents the $P$ value for "site" and D that for "diet". Only significant results have been shown. Individual site differences (diet) are marked with an asterisk * $(P<0.05$, post-hoc Tuckey's test).

Table 2 WAT weight, protein and RNA content of female Wistar rats fed for $30 \mathrm{~d}$ with a cafeteria diet

\begin{tabular}{|c|c|c|c|c|c|c|}
\hline Parameter & Site & Unit & Control & Cafeteria & $\mathrm{P}$ diet & P site \\
\hline \multirow{5}{*}{ WAT weight } & SC & $\mathrm{g}$ & $7.02 \pm 0.25$ & $12.3 \pm 0.3$ & $<0.0001$ & $<0.0001$ \\
\hline & $\mathrm{ME}$ & & $3.92 \pm 0.33$ & $9.02 \pm 1.25$ & & \\
\hline & $\mathrm{RE}$ & & $2.79 \pm 0.35$ & $7.81 \pm 0.77$ & & \\
\hline & $\sum$ WAT & $\mathrm{g}$ & $18.6 \pm 0.93$ & $41.0 \pm 3.5$ & 0.0001 & - \\
\hline & & $\%$ BW & $8.05 \pm 0.52$ & $15.2 \pm 0.5$ & $<0.0001$ & - \\
\hline \multirow[t]{2}{*}{ Protein } & SC & $m g g^{-1}$ & $51.8 \pm 3.3$ & $41.2 \pm 4.3$ & 0.0010 & $<0.0001$ \\
\hline & $\mathrm{RE}$ & & $62.9 \pm 4.7$ & $50.7 \pm 1.3$ & & \\
\hline \multirow[t]{4}{*}{ RNA } & SC & $\mu \mathrm{g} \mathrm{g}^{-1}$ & $219 \pm 19$ & $154 \pm 15$ & $<0.0001$ & $<0.0001$ \\
\hline & ME & & $793 \pm 88$ & $92.0 \pm 5.5$ & & \\
\hline & $\mathrm{PO}$ & & $119 \pm 10$ & $57.6 \pm 4.1$ & & \\
\hline & $\mathrm{RE}$ & & $78.4 \pm 8.8$ & $38.4 \pm 6.2$ & & \\
\hline \multirow{2}{*}{ RNA/protein ratio } & SC & $\operatorname{mg} g^{-1}$ & $4.25 \pm 0.13$ & $4.77 \pm 0.86$ & $<0.0001$ & $<0.0001$ \\
\hline & ME & & $9.49 \pm 1.13$ & $1.87 \pm 0.68$ & & \\
\hline
\end{tabular}

The data are the mean \pm SEM of 6 different animals per group. Statistical significance of the differences between groups (two-way ANOVA: diet and WAT site). $\mathrm{BW}=$ body weight. $\mathrm{SC}=$ subcutaneous WAT; $\mathrm{ME}=$ mesenteric WAT; PO = periovaric WAT; RE = retroperitoneal WAT. The sum of these four sites is indicated as $\sum$ WAT. 
Plasma parameters were all within the expected range and were similar to previously published data. ${ }^{26,35}$ They are presented in ESI Table $1 . \dagger$

Fig. 2 depicts the data in Table 1 but tissue protein and RNA are presented as the total amount present in the whole site for the direct comparison of the eventual changes induced by the diet. There were overall significant differences of cafeteria $v s$. controls for protein, although they were not observed in subcutaneous WAT, nor between sites. When analyzing RNA, the differences were less patent; cafeteria diet-feeding resulted in a marked overall difference between sites, but not diet. In fact, the only site showing a marked difference
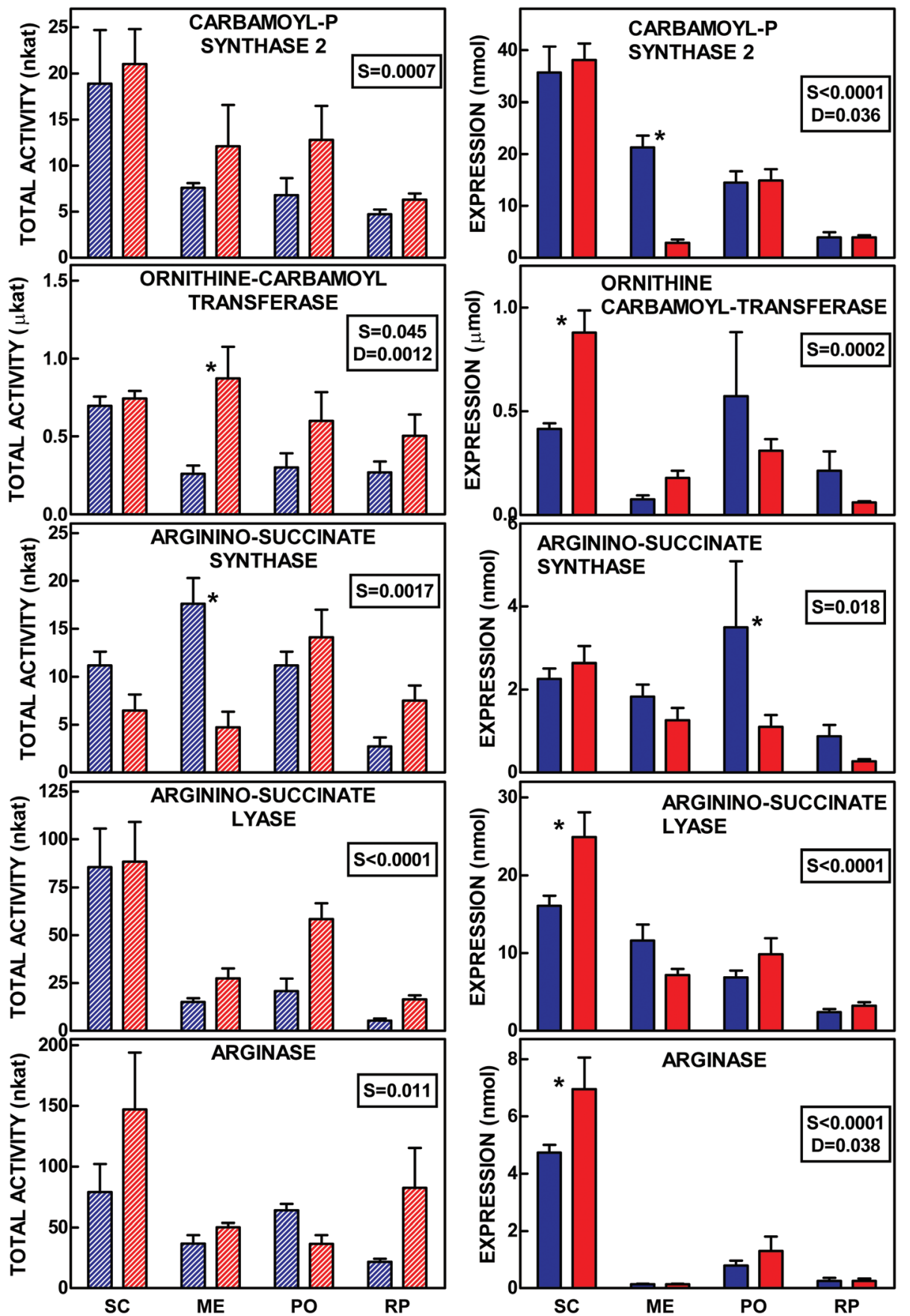

Fig. 3 Total activity and gene expression of urea cycle enzymes present in the mass of WAT tissue sites of female rats fed control or cafeteria diets. The data are the mean \pm SEM of 6 different animals. Left, enzyme activities: blue dashed columns: control diet; red dashed columns: cafeteria diet. Right, gene expressions: blue columns: control diet; red columns: cafeteria diet. WAT sites: $\mathrm{SC}=$ subcutaneous, $\mathrm{ME}=$ mesenteric, $\mathrm{PO}=$ periovaric; RP = retroperitoneal. The expression data for arginase are the sum of Arg1 and Arg2 for subcutaneous WAT, and of Arg1 for all other sites. Statistical significance of the differences between groups (two-way ANOVA). S represents the $P$ value for "site" and D that for "diet". Only significant results have been shown. Individual site differences (diet) are marked with an asterisk * $(P<0.05$, post-hoc Tuckey's test). 
between the diet groups was mesenteric, in which the total RNA content of the tissue was reduced to roughly one third with cafeteria diet.

Fig. 3 shows the urea cycle enzyme activities present in the whole site (nkat or $\mu$ kat), and the expressions of the corresponding genes (i.e. in nmol or $\mu$ mol of the specific gene mRNA), also expressed with respect to the whole site. The argi- nase value for activity corresponds to the sum of arginases 1 and 2; the latter being expressed only in subcutaneous WAT. The corresponding value for gene expression reflects also the sum of Arg1 and Arg2. There was clear discordance between the total enzyme activities and the mRNA content for their coding genes in different sites. In all the cases (activities and expressions), there was a significant difference between the
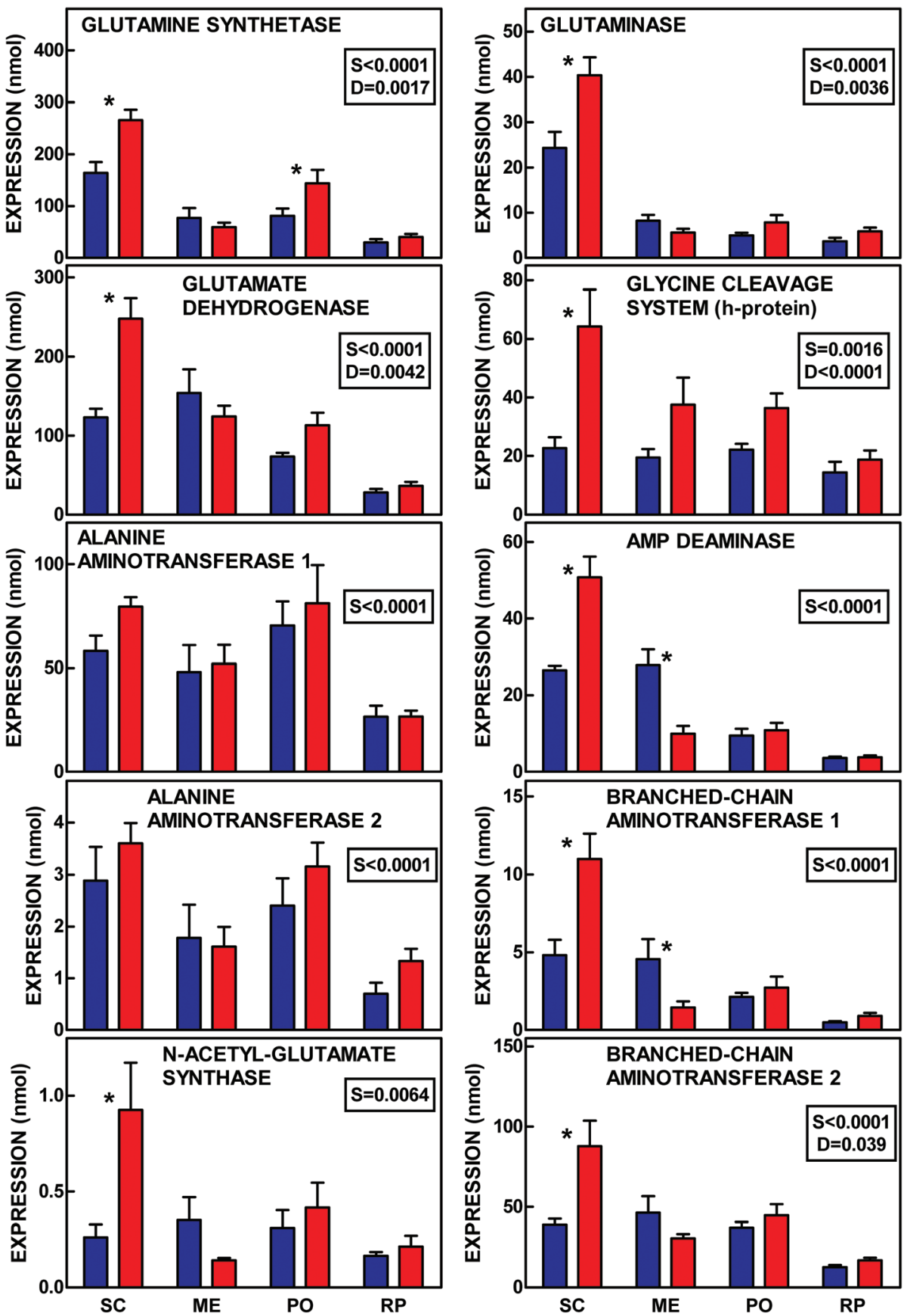

Fig. 4 Total expression (i.e. specific mRNA content) of amino acid metabolism enzyme genes present in the mass of WAT tissue sites of female rats fed control or cafeteria diets. The data are the mean \pm SEM of 6 different animals. Blue columns: control diet; red columns: cafeteria diet. WAT sites: $\mathrm{SC}=$ subcutaneous, $\mathrm{ME}=$ mesenteric, $\mathrm{PO}=$ periovaric; $\mathrm{RP}=$ retroperitoneal. Statistical significance of the differences between groups (two-way ANOVA). S represents the $P$ value for "site" and D that for "diet". Only significant results have been shown. Individual site differences (diet) are marked with an asterisk * $(P<0.05$, post-hoc Tuckey's test). 
WAT sites. However, the overall effects of diet were minimal, significant only for ornithine carbamoyl-transferase activity and the expressions of arginase and carbamoyl-P synthase. In general, subcutaneous WAT showed higher activities for carbamoyl-P synthase 2, arginino-succinate lyase and arginase activities (and expressions). Cafeteria diet induced a marked increase in ornithine carbamoyl-transferase activity and decrease in arginino-succinate synthase activity in mesenteric WAT. This diet increased ornithine carbamoyl-transferase, argi-

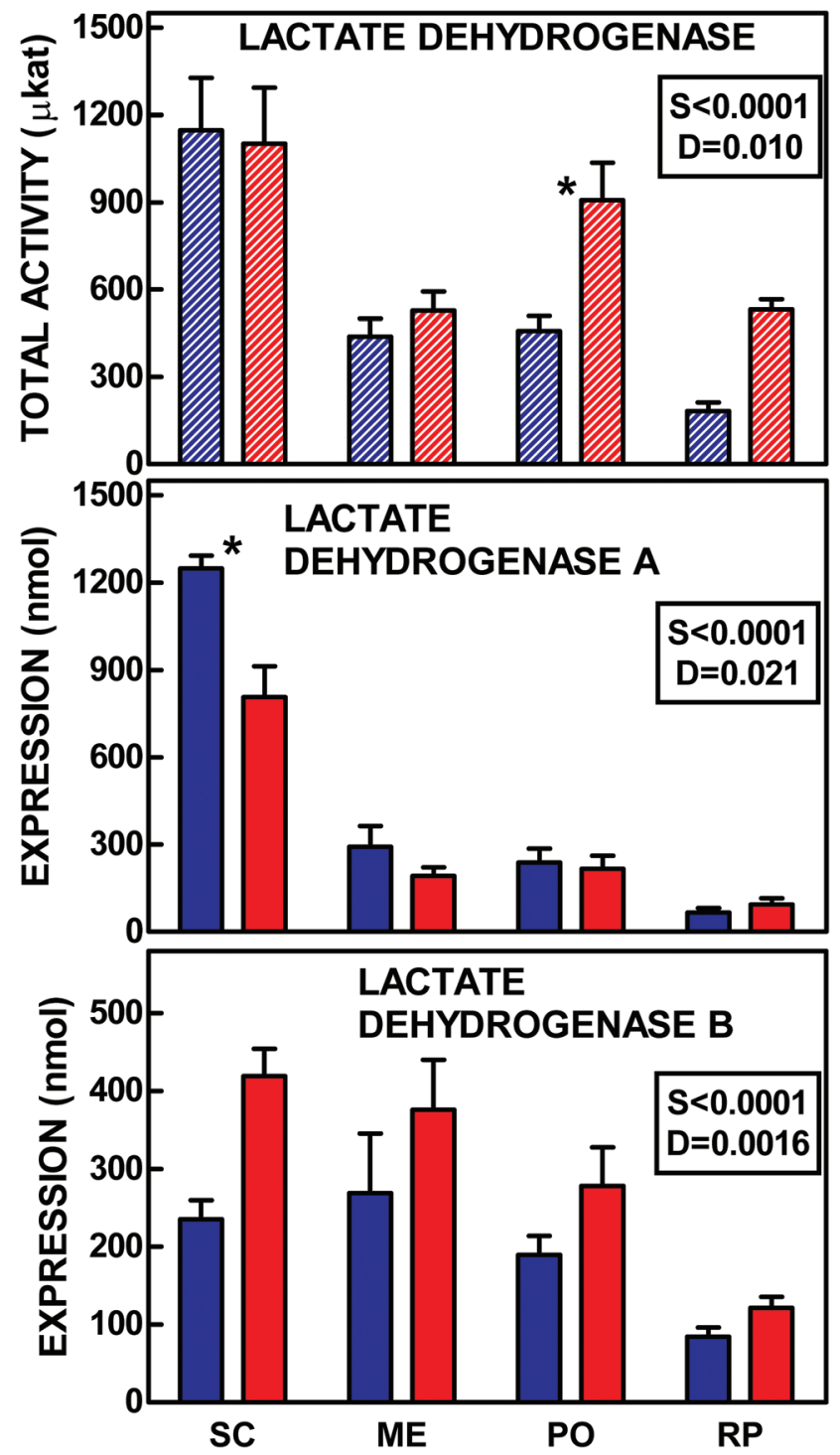

Fig. 5 Total activity and expression of lactate dehydrogenase genes present in the mass of WAT tissue sites of female rats fed control or cafeteria diets. The data are the mean \pm SEM of 6 different animals. Activity: blue dashed columns: control diet; red dashed columns: cafeteria diet. Expressions: blue columns: control diet; red columns: cafeteria diet. WAT sites: $\mathrm{SC}=$ subcutaneous, $\mathrm{ME}=$ mesenteric, $\mathrm{PO}=$ periovaric; RP = retroperitoneal. Statistical significance of the differences between groups (two-way ANOVA). S represents the $P$ value for "site" and D that for "diet". Only significant results have been shown. Individual site differences (diet) are marked with an asterisk * $(P<0.05$, post-hoc Tuckey's test). nino-succinate lyase and the expressions of both arginases in subcutaneous WAT; cafeteria feeding decreased the expression of carbamoyl-P synthase in mesenteric WAT and argininosuccinate synthase in periovaric WAT. In spite of punctual variations, and the marked differences between sites, the general trend was to maintain the same amount of active enzyme and specific gene mRNA in the WAT sites, with only limited changes, despite their different mass and dietary treatment.

Fig. 4 shows the expressions of gene coding for proteins related to ammonia/2-amino $\mathrm{N}$ metabolism in four sites of WAT in control or cafeteria diet-fed female rats. All genes showed significant differences in expression between sites, but the overall effects of diet were limited to Glul, glutamine synthetase; Glud1, NADP ${ }^{+}$glutamate dehydrogenase; Gls, glutaminase; Gcsh, h protein of the glycine cleavage system; and Bcat2, branched-chain amino acid aminotransferase (mitochondrial). In addition to these generalized modifications, specific sites showed significant changes with cafeteria diet feeding, i.e. increases in subcutaneous WAT for all genes except Ala1 and Ala2. On the other side, mesenteric WAT also showed significant decreases for Amp2, and Bcat1; Glul was increased in periovaric WAT.

By comparison, Fig. 5 depicts the WAT site lactate dehydrogenase activity ( $\mu$ kat in the whole tissue mass) and the corresponding values for gene coding for both the lactate dehydrogenases, a and b (Ldha, Ldhb). In addition to a significant difference for site, both lactate dehydrogenase activity and Ldha changed significantly with diet. Periovaric WAT activity was higher in cafeteria diet-fed rats, whereas the expression of $L d h a$ and $L d h b$ were lower in subcutaneous WAT under the hyperlipidic diet.

The data of Fig. 3-5 are also presented in the more usual form of activity/expression per unit of protein weight in the ESI, Tables 2-5.†

\section{Discussion}

Cafeteria diet is a widely used and robust model of metabolic syndrome in rodents, ${ }^{36-38}$ characterized by voluntary hyperphagia and grossly elevated fat intake which results in rapid weight gain. In addition, cafeteria diet feeding induces glucose intolerance and inflammation in rodents. ${ }^{38}$ It has been found that relatively short periods of exposure to a cafeteria diet are enough to disturb the metabolic response to food availability in key tissues, and hence alter energy homeostasis, particularly in WAT. These changes often induce exacerbated body fat accumulation and increased metabolic risk, often with no apparent or minimal effects on body weight. ${ }^{39}$ Thus, this model provides a unique animal platform to study the biochemical mechanisms that characterize obesity and the metabolic syndrome. The main result derived from the present study has been rather surprising, since, in spite of doubling the size of WAT because of one month of eating an energy-rich cafeteria diet, the actual transforming capacity of most amino acid metabolism enzymes in WAT remained practically 
unchanged with respect to the whole adipose tissue. This was a consequence of only limited changes in the overall enzyme activity, but also because of a generalized decrease in the expression of the corresponding genes when related to tissue weight. The considerable increase in the size of WAT was mainly due to the accumulation of fat, but protein followed suit. The most marked differences were in the RNA content, which actually decreased in most sites, largely compensating the disproportion in size.

The remarkable stability of urea cycle enzyme activities observed here contrasts with the decreases observed in the liver. ${ }^{21}$ However, one can wonder whether the actual importance of the changes in liver functions would be appreciated as so deep if the activity/expression were corrected by the actual size (and, better, including blood flow) ${ }^{13}$ of the organ. The enormous change that WAT experiences when challenged with an excess of nutrients, however, is not comparable to any other "regular" organ. We speculated whether part of the problems derived from an enlarged (in fact engorged) WAT would be a consequence of the disproportion of its mass with respect to all other tissues; however, what we found experimentally was a clear downregulation of enzyme activities that practically compensated the increase in tissue mass.

Lowered blood flow ${ }^{40}$ may be - also - part of the homoeostatic adjustment to increased WAT mass, since lower relative blood flow is consistent with decreased metabolic activity (according to the low total RNA data). In addition, excess "inert" triacylglycerol stores reduce considerably the active tissue mass. In any case, the maintenance of most enzyme activities/gene expressions seems to be a consequence of a generalized homoeostatic adjustment preventing the eventual loss of balance between organ (size) and function. We are aware that the form of expression we used here must be complemented with other, more common, forms of data representation (presented in the ESI Tables 2-5†). The results obtained made us suggest that the analysis we carried out on key aspects of amino acid metabolism should be applied to the most critical aspects of glucose handling and lipogenesis too, to check whether the increased WAT size is countered by a generalized diminution of its metabolic activity. Our own data suggest that diet has only a limited (if any) effect on lactate metabolism in vivo. ${ }^{13}$ The results presented here corroborate the conclusions obtained from tissue lactate levels and enzyme activities. ${ }^{13}$ Lactate dehydrogenase (and lactate metabolism) is diminished in adipocytes of obese animals, ${ }^{13,41}$ but the overall handling capacity is maintained as we have shown here.

The results presented highlight a differential role for subcutaneous WAT, at least for amino acid metabolism, since its cumulative activity for most enzymes was higher than the combined activities of the other three sites studied. The widely known metabolic difference between subcutaneous and "visceral" WAT, ${ }^{42,43}$ in this case represented by the mesenteric site, was in part confirmed by a loss of amino acid metabolizing activity in this site in rats fed a cafeteria diet; this effect was largely compensated by an increase in subcutaneous WAT activity. This shift of function from the splanchnic bed to peri- pheral tissues agrees with the loss of energy substrate control of the liver in obesity. ${ }^{44,45}$ It is also in agreement with the predominant role of peripheral tissues as suppliers of substrates under starvation: muscle exports 3C units ${ }^{46}$ and WAT fatty acids ${ }^{47}$ (and 3C units too ${ }^{14}$ ) after the liver exhausted its glycogen reserves and when the intestine cannot supply dietary-derived nutrients. ${ }^{48}$ It has been postulated that a high availability of circulating fatty acids spurns insulin resistance as a way to save glucose, and this effort is counterproductive when the fatty acids come from the diet (i.e. together with glucose) and not from peripheral lipolysis. ${ }^{49}$ Under these overfeeding conditions, thus, the problem of disposing of excess glucose becomes a priority. Moreover, since 2-amino $\mathrm{N}$ preservation is critical for survival (an evolutionary fiat), ${ }^{19}$ consequently, amino acids become even more difficult to dispose of through the well-controlled splanchnic catabolic pathways. $^{50}$

The lowered amino acid disposal capacity observed in cafeteria-diet fed rats ${ }^{21,37}$ stems from a lowered or unfocussed function of the liver (in fact liver-intestine as a unit), and is reflected in lower levels and excretion of urea. ${ }^{21,37}$ We wanted to check whether the newly found WAT urea cycle could somehow compensate the disorder caused in the liver by metabolic syndrome, perhaps through the activation of peripheral amino acid catabolism. The surprising lack of change in the peripheral urea cycle suggests a maintenance of its function in spite of lowered activity/gene expression per $g$ of tissue. Since the combined activity of WAT in both dietary groups was higher for a number of enzyme activities than in the liver, ${ }^{51}$ we must assume that, at least in part, the production of urea may be taken up by WAT in the obese. The peculiar increase in enzyme activities observed in subcutaneous WAT suggests that this site (the most "peripheral" of those studied here) may play a role more important than usually assumed in amino acid handling. High Nags expression may indicate an activation of the synthesis of ornithine, ${ }^{52}$ in agreement with the role of WAT as a postulated peripheral producer of citrulline. ${ }^{53}$ This increase may help compensate the alteration of citrulline synthesis by the intestine ${ }^{54}$ in obesity.

Glul increased expression in subcutaneous WAT of rats fed a cafeteria diet, suggests that part of the ammonium probably produced by the increased expression of $A m p 2$ and the glycine cleavage system, but also Gls (to a lower extent), is not driven towards the urea cycle, but maintained as glutamine or glutamate (increased expression of Glud1). However, there is a clear role of subcutaneous WAT in the catabolism of 2-amino $\mathrm{N}$ as clearly shown by the considerable increases in the expression of Bcat1 and Bcat2, marking this site as a probably significant place for the catabolism of branched-chain amino acids, as previously suggested. ${ }^{55}$ This contrasts with the lack of changes in $G p t$ and Gpt2, in spite of the known release of alanine by adipocytes. ${ }^{56}$

We can summarize our findings by stating that increased WAT mass produced by cafeteria diet feeding does not translate into higher overall WAT metabolic activity, but to its maintenance: the enzyme activities and RNA are diluted in a 
reversed proportion to the increase in mass of the tissue. This is logical from a homoeostatic point of view, since, under this assumption, the only significant difference in the WAT function from lean to obese would be the storage of fat. This question needs further metabolic analyses to check whether lipid metabolism follows the same trend, and, further, to determine the differences between the initial phases of WAT engorgement and a relative steady state as that observed here.

The other key point is the remarkable constancy of the WAT urea cycle under high energy availability, under the pressure of excess 2-amino $\mathrm{N}$ availability and the need to dispose of it against the powerful mechanisms of preservation of amino acids. The only clear trend observed was the shift in amino acid metabolism from abdominal WAT, mainly mesenteric, to an acquired metabolic predominance of subcutaneous WAT, in line with the displacement of metabolic activity from the splanchnic bed to peripheral tissues typical of starvation and, contrastingly, of the excess of nutrient availability.

Overall, the results of this study give support to the consideration of WAT as an organ, ${ }^{57}$ disperse ${ }^{58}$ but under uniform control. $^{35}$ The metabolic peculiarities between its different sites, ${ }^{59-61}$ and their ability to adapt to different energy availability conditions only add to the protean nature of the adipose tissue. Last, but not least, we have presented additional evidence on the role of WAT in amino acid metabolism, a question difficult to discuss because of the absence of sufficient studies with which we can compare and check our results.

\section{Authors' contributions}

X. R, M. A and J. A. F. L designed the study; S. Ar and S. Ag carried out the experiments; S. Ar and J. A. F. L calculated the data and carried out statistical analyses; J. A. F. L wrote the first manuscript draft. All authors discussed the text and contributed to the final version.

\section{Conflict of interests}

The authors declare that they have no conflict of interest.

\section{Acknowledgements}

This study was done with the partial support of grants of the Plan Nacional de Investigación en Biomedicina (SAF201234895) and the Plan Nacional de Ciencia y Tecnología de los Alimentos (AGL-2011-23635) of the Government of Spain, as well as of CIBER-OBN web of biomedical research. S. Agnelli was the recipient of a Leonardo da Vinci fellowship, and S. Arriarán a predoctoral fellowship of the Catalan Government, in both cases covering part of the time invested in this study.

\section{References}

1 A. Sclafani and D. Springer, Physiol. Behav., 1976, 17, 461.

2 I. Rafecas, M. Esteve, J. A. Fernández-López, X. Remesar and M. Alemany, Nutr. Res., 1994, 14, 1077.

3 B. P. Sampey, A. M. Vanhoose, H. M. Winfield, A. J. Freemerman, M. J. Muehlbauer, P. T. Fueger, C. B. Newgard and L. Makowski, Obesity, 2011, 19, 1109.

4 M. B. Zimmermann and I. Aeberli, Int. J. Obes., 2008, 32 (Suppl. 6), S11.

5 R. Monteiro and I. Azevedo, Mediators Inflammation, 2010, 2010, 289645.

6 M. Motie, L. S. Evangelista, T. Horwich, D. Lombardo, F. Zaldivar, M. Hamilton and G. C. Fonarow, Exp. Ther. Med., 2014, 8, 181.

7 D. B. West, A. A. Francendese, M. R. C. Greenwood and W. A. Prinz, Am. J. Physiol., 1987, 253, R228.

8 H. M. Cao, J. Endocrinol., 2014, 220, T47.

9 M. Alemany, J. Clin. Endocrinol. Metab., 2011, 96, 66.

10 K. N. Frayn, Proc. Nutr. Soc., 2011, 60, 375.

11 P. Trayhurn, B. Wang and I. S. Wood, Br. J. Nutr., 2008, 100, 227.

12 D. Sabater, S. Arriarán, M. M. Romero, S. Agnelli, X. Remesar, J. A. Fernández-López and M. Alemany, Sci. Rep., 2014, 4, 3663.

13 S. Arriarán, S. Agnelli, D. Sabater, X. Remesar, J. A. Fernández-López and M. Alemany, PLoS One, 2015, 10, e0119572.

14 M. T. van der Merwe, N. J. Crowther, G. P. Schlaphoff, I. H. Boyd, I. P. Gray, B. I. Joffe and P. N. Lönnroth, J. Clin. Endocrinol. Metab., 1998, 83, 4084.

15 G. H. Goossens and E. E. Blaak, Curr. Opin. Clin. Nutr. Metab. Care, 2012, 15, 539.

16 L. Hodson, S. M. Humphreys, F. Karpe and K. N. Frayn, Diabetes, 2013, 62, 1417.

17 I. de Blaauw, N. E. P. Deutz and M. F. von Meyenfeldt, Am. J. Physiol., 1996, 270, G298.

18 T. Aikawa, H. Matsutaka, H. Yamamoto, T. Okuda and E. Ishikawa, J. Biochem., 1973, 74, 1003.

19 P. Felig, O. E. Owen, J. Wahren and G. F. Cahill, J. Clin. Invest., 1969, 48, 584.

20 P. Tessari, R. Barazzoni, M. Zanetti, E. Kiwanuka and A. Tiengo, Baillière's Clin. Endocrinol. Metab., 1996, 10, 511.

21 T. Barber, J. R. Viña, J. Viña and J. Cabo, Biochem. J., 1985, 230, 675.

22 M. Esteve, I. Rafecas, X. Remesar and M. Alemany, Int. J. Obes., 1991, 16, 237.

23 M. Esteve, I. Rafecas, J. A. Fernández-López, X. Remesar and M. Alemany, Biochem. Mol. Biol. Int., 1993, 29, 1069.

24 F. J. López-Soriano and M. Alemany, Arch. Int. Physiol. Biochim., 1986, 94, 121.

25 S. Arriarán, S. Agnelli, X. Remesar, J. A. Fernández-López and M. Alemany, $R S C A d v$., 2015, 5, 93403.

26 R. Ferrer-Lorente, C. Cabot, J. A. Fernández-López and M. Alemany, Life Sci., 2005, 77, 2051. 
27 E. Prats, M. Monfar, R. Iglesias, J. Castellà and M. Alemany, Physiol. Behav., 1989, 45, 263.

28 I. Rafecas, M. Esteve, J. A. Fernández-López, X. Remesar and M. Alemany, Int. J. Obes., 1992, 16, 775.

29 L. Arola, E. Herrera and M. Alemany, Anal. Biochem., 1977, 82, 236.

30 O. H. Lowry, R. W. Rosebrough, A. L. Farr and R. J. Randall, J. Biol. Chem., 1951, 193, 265.

31 S. Arriarán, S. Agnelli, J. A. Fernández-López, X. Remesar and M. Alemany, J. Enzyme Res., 2012, 3, 29.

32 A. Vassault A, Methods Enzym. Anal., 1983, 3, 118.

33 M. M. Romero, M. M. Grasa, M. Esteve, J. A. FernándezLópez and M. Alemany, Nutr. Metab., 2007, 4, 26.

34 G. Bamias, D. Goukos, E. Laouidi, I. G. Balla, S. I. Siakavellas, G. L. Daikos and S. D. Ladas, Inflammatory Bowel Dis., 2013, 19, 2840.

35 M. M. Romero, S. Roy, K. Pouillot, M. Feito, M. Esteve, M. M. Grasa, J. A. Fernández-López, M. Alemany and X. Remesar, PLoS One, 2014, DOI: 10.1371/journal. pone.0090995.

36 M. Esteve, I. Rafecas, J. A. Fernández-López, X. Remesar and M. Alemany, Physiol. Behav., 1994, 56, 65.

37 D. Sabater, S. Agnelli, S. Arriarán, J. A. Fernández-López, M. M. Romero, M. Alemany and X. Remesar, BioMed Res. Int., 2014, 2014, 959420.

38 B. P. Sampey, A. M. Vanhoose, H. M. Winfield, A. J. Freemerman, M. J. Muehlbauer, P. T. Fueger, C. B. Newgard and L. Makowski, Obesity, 2011, 19, 1109.

39 H. Castro, C. A. Pomar, C. Picó, J. Sánchez and A. Palou, Int. J. Obes., 2015, 39, 430.

40 K. N. Frayn and F. Karpe, Int. J. Obes., 2014, 38, 1019.

41 F. Rotondo, M. M. Romero, J. A. Fernández-López, X. Remesar and M. Alemany, Obes. Facts, 2015, 8(Suppl. 1), 170.

42 F. Bertile, F. Criscuolo, H. Oudart, Y. le Maho and T. Raclot, Biochem. Biophys. Res. Commun., 2003, 307, 540.

43 B. Zahorska-Markiewicz, Adv. Med. Sci., 2006, 51, 111.
44 T. Wasada, T. Kasahara, J. Wada, S. Jimba, R. Fujimaki, T. Nakagami and Y. Iwamoto, Metab. Clin. Exp., 2008, 57, 980.

45 C. E. Ndumele, K. Nasir, R. D. Conceiçao, J. A. M. Carvalho, R. S. Blumenthal and R. D. Santos, Arterioscler., Thromb., Vasc. Biol., 2011, 31, 1927.

46 C. F. Cori, Curr. Top. Cell. Regul., 1981, 18, 377.

47 P. J. Randle, P. B. Garland, C. N. Hales and E. A. Newsholme, Lancet, 1963, 281, 785.

48 M. Alemany, RSC Adv., 2013, 3, 1636.

49 G. F. Cahill, Annu. Rev. Nutr., 2006, $26,1$.

50 M. Alemany, Nutr. Res. Rev., 2012, 25, 18.

51 S. Agnelli, S. Arriarán, L. Oliva, X. Remesar, J. A. FernándezLópez and M. Alemany, RSC Adv., 2016, 6, 11278.

52 K. Tujioka, S. Lyou, E. Hirano, A. Sano, K. Hayase, A. Yoshida and H. Yokogoshi, J. Agric. Food Chem., 2002, 50, 7467.

53 S. Arriarán, S. Agnelli, X. Remesar, J. A. Fernández-López and M. Alemany, RSC Adv., 2015, 5, 93403.

54 J. G. Henslee and M. E. Jones, Arch. Biochem. Biophys., 1982, 219, 186.

55 M. A. Herman, P. X. She, O. D. Peroni, C. J. Lynch and B. B. Kahn, J. Biol. Chem., 2010, 285, 11348.

56 K. Snell and D. A. Duff, Biochem. Biophys. Res. Commun., 1977, 77, 925.

57 S. Cinti, Prostaglandins, Leukotrienes Essent. Fatty Acids, 2005, 73, 9.

58 A. Giordano, A. Smorlesi, A. Frontini, G. Barbatelli and S. Cinti, Eur. J. Endocrinol., 2014, 170, R159.

59 A. Boivin, G. Brochu, S. Marceau, F. S. Hould and A. Tchernof, Metab. Clin. Exp., 2007, 56, 533.

60 A. Tchernof, C. Bélanger, A. S. Morisset, C. Richard, J. Mailloux, P. Laberge and P. Dupont, Diabetes, 2006, 55, 1353.

61 J. Östman, P. Arner, P. Engfeldt and L. Kager, Metabolism, 1979, 28, 1198. 